\title{
Hemşirelik Eğitiminde Teknoloji Kullanımı ve Örnek Uygulamalar
}

\section{Fadime ULUPINAR ${ }^{1}$, Şükrü Anıl TOYGAR ${ }^{2}$}

\section{The Use of Technology in Nursing Education and Sample Practices}

\begin{tabular}{l} 
ARTICLE INFO \\
\hline Article History: \\
Date Submitted:08.01.2020 \\
Date Accepted:03.05.2020 \\
\hline JEL Classification: \\
I10, \\
I19, \\
I20
\end{tabular}

Keywords:

Nursing,

Technology,

Education

\begin{abstract}
With technology, a rapid change in health care practices have occured. In this review, it is aimed to emphasize the importance of technology for nursing education and to introduce some technology applications used in nursing education. The widespread use of technology in nursing services due to the need for nursing workforce affects nursing education. Both the increase in expectations in the quality of delivery of developing health services and the efforts to increase the competence of students have made use of technology in nursing practice a necessity. In the developing world of education, the use of technology is expected to serve as a bridge in the gap between theoretical knowledge and clinical practice, which is the problem of traditional methods. Through these applications, students can see the result of the action by finding countless possibilities of experimentation, which has a positive effect on learning success. For an effective training that can adapt to rapidly changing education and maintenance technologies, a change process involving all parties should be planned. It is thought that the presence of the generation of educators and students who can actively use these technologies will have an important role in carrying the nursing profession to the future. In this review, the importance of the use of technology in nursing education and some of the applications of technology used in nursing education in the world are specified.
\end{abstract}

\footnotetext{
${ }^{1}$ Öğretim Görevlisi, Karamanoğlu Mehmetbey Üniversitesi Ermenek MYO, Sağ. Kur. İşl. Programı

${ }^{2}$ Doktor Öğretim Üyesi, Selçuk Üniversitesi Hemşirelik Fakültesi, Hemşirelikte Yönetim ABD
} 


\section{Özet}

Teknolojiyle birlikte sağlık bakım uygulamalarında hızlı bir değişim meydana gelmektedir. $\mathrm{Bu}$ derlemede hemşirelik eğitimi ve eğiticileri için teknolojinin önemini vurgulanmak ve hemşirelik eğitiminde kullanılan bazı teknoloji uygulamalarının tanıtılması amaçlanmaktadır. Hemşire işgücü ihtiyacı nedeniyle hemşirelik hizmetlerinde teknoloji kullanımının yaygınlaşması hemşirelik eğitimini etkilemektedir. Gerek gelişen sağlık hizmetlerinin sunum kalitesinde beklentilerin artması ve gerekse öğrencilerin yetkinliğini artırma çabaları hemşirelik uygulamalarında teknoloji kullanımını zorunluluk haline getirmiştir. Gelişen değişen dünyada eğitim alanında, geleneksel yöntemlerin sorunu olan teorik bilgiyle klinik uygulama arasındaki boşluğun doldurulmasında teknoloji kullanımının bir köprü vazifesi görmesi beklenmektedir. Bu uygulamalar sayesinde öğrenciler sayısız deneme imkânı bularak yaptığı eylemin sonucunu görebilmekte bu durum öğrenme başarısını olumlu yönde etkilemektedir. Hızla değişen eğitim ve bakım teknolojilerine ayak uydurabilen etkin bir eğitim için tüm tarafların birlikte yer aldığı bir değişim sürecinin planlanması gerekmektedir. Bu teknolojileri aktif bir şekilde kullanabilen eğitici ve öğrenci kuşağının varlığının hemşirelik mesleğinin geleceğe taşınmasında önemli bir rolünün olacağı düşünülmektedir. Bu derlemede hemşirelik eğitiminde teknoloji kullanımın önemine ve dünyada hemşirelik eğitiminde kullanılan bazı teknoloji uygulamaları hakkında bilgilere yer verilmektedir.

\section{Anahtar kelimeler: Hemşirelik, Teknoloji, Eğitim, Eğitici}

\section{Giriş}

Hayatımızın birçok alanında kullanılan ve vazgeçilmez bir unsur haline gelen teknoloji, eğitim alanında da etkisini göstermektedir. Hemşirelik eğitimini de etkileyen teknoloji bu alanda en önemli gelişme ve değişmelerden biri olarak kabul edilmektedir (Axley, 2008; Merrill, 2015). Günümüzde üniversitelerin hemşirelik bölümlerinden mezun olanların birçok teknolojik yeterliliğe sahip olması beklenmektedir. Bilgisayarlar, tablet ve telefonlar gibi akıllı cihazlar, dijital iletişim, veri işleme, multimedya sunumları, profesyonel belgeler oluşturmak için gerekli bilgisayar yazılımları gibi teknolojik uyumlar günümüzde çoktan hemşirelerin görev alanı haline gelmiştir (van Houwelingen vd., 2016). Bu nedenle teknolojik gelişmelerin 
hızı ve bunun eğitim hizmetlerine yansıması sadece eğitim alanların değil, eğitim hizmeti sunanların da bu değişime ayak uydurmasını zorunlu kılmaktadır (Risling, 2017). Bu teknolojik evrimin hem teorik hem de uygulamada rehberlik görevi üstlenecek hemşirelik eğitimcilerinden bağımsız olmasının söz konusu olmadığı söylenebilir. Bütünsel bir sağlık bakım anlayışı için, takibi zor olan bu hızlı değişimin öncülüğünü, hemşirelik eğiticilerinden başlatmak bir zorunluluk olarak görülmektedir (C. L. Foronda vd., 2017). Böylelikle eğiticilerin eğitilmesini gerektiren ve alandaki gelişime paralel olarak yeni uygulamalarla güncelliğini korunmasını esas alan daimi bir döngü söz konusudur (Risling, 2017).

Sağlık eğitiminde "deneme-yanılma" ya da "görme, duyma, yapma” yolu ile öğrenme, en eski öğretim yöntemlerden biri (Karadağ ve Uçan, 2006) olmasına rağmen; hasta güvenliği ve hasta haklarının öneminin giderek artması, ilgi alanlarında ilerleme isteğiyle öğrencilerin yetkinliğini artırma çabaları interaktif eğitim yöntemlerini benimsenmesini hızlandırmıştır (Şendir, 2013). Hemşirelik eğitiminin mevcut haliyle sınırlı kalmaması, teknolojiyle entegre edilmiş gelecek nesillerin hemşirelerini yetiştirmek için önümüzdeki on y1lın planlanan uygulamalarına hazır hale gelmesi oldukça önemli gözükmektedir.

Müfredatların revize edilmesi genellikle karmaşık ve uygulamada güçlüklerin çokça yaşandığı bir süreçtir. Daha esnek ve güncellenebilir eğitim programlarına ihtiyaç olduğu görülmektedir. Yani hemşire eğitimi veren ve alan kişilerin birlikte yer aldığ bir değişim sürecini planlamak, içinde bulunulan şartların gerektirdiği bilişim donanımına sahip olmak, belki de eğitim sürecinde hemşireleri alanlara ayırmak ve buna uygun teknolojik yeterlilikleri tamamlayarak hazır hale getirmek çözüm olabilir (C. L. Foronda vd., 2017).

Hemşirelik bakım hizmetlerindeki uygulamalar on yıl öncesine kadar hemşirelerin kendi gözlem ve deneyimlerinden ya da sosyal çevresindeki sağlık çalışanlarının tecrübelerinden faydalanarak gerçekleştirilirken, günümüzde ise hassas ölçüm yapabilen cihazlar kullanılmakta fakat bu çıktıları yine eldeki elektronik verileri temel alarak sağlık çalışanları tarafından yorumlamaktadır. Yakın gelecekte ise hassas ölçüm yapabilen çok sayıdaki cihazdan gelen verileri entegre eden, genişletilmiş elektronik kayıtları kullanarak değerlendiren, eylem planı hazırlayabilen yapay zeka teknolojilerinin kullanılması 
öngörülmektedir. Daha uzun bir gelecekte ise bakım hizmetindeki birçok eylemin robotlar tarafından gerçekleştirilmesi gündemdedir.

Sayısal teknolojilerdeki ilerlemeler, fiziksel yakınlık söz konusu olmadan hastayı ve bakım verenleri bir araya getirerek, tele sağlık-tele tıp uygulamalarını artırmıştır (Heller vd., 2009). Teknoloji günümüzde o kadar hızlı değişmektedir ki önümüzdeki on yıl için bile sağlıkla ilgili olası değişim senaryolarını öngörebilmek oldukça güçtür (Risling, 2017). Henüz kullanılmaya başlanan mobil cihazlar, elektronik sağlık kayıtları, giyilebilir teknolojiler, Artırılmış Gerçeklik uygulamaları, üç boyutlu yazıcılar ve robotik teknolojilerin gelişim hızı göz önünde bulundurulursa gelecek on yılda, şu anki durumdan çok daha farklı bir hemşirelik eğitimi sunulabileceği düşünülmektedir (Risling, 2017). Bu nedenle, hemşirelerin bilgisayar teknolojisini aktif ve etkili bir şekilde kullanabilmeleri bir gereklilikten çok zorunluluk halini almıştır (Heller vd., 2009). Hatta sadece öğrenciler ve eğiticiler değil toplumdaki tüm bireyler, teknoloji tabanlı yaşam ve çalışma ortamlarına uyum sağlamak zorundadır (Eby, 2013).

International Telecommunication Union (ITU) raporunda, 2000 y1lında 400 milyon olan internet kullanıcısının, 2016 yılında 3,5 milyar olduğu belirtmiştir (ITU, 2015). We Are Social ve Hootsuite tarafından yayımlanan "Digital in 2019" raporuna göre, 2019 y1lında 4,38 milyar internet kullanıcısı, 5,11 milyar mobil telefon kullanıcısı mevcuttur (HOOTSUITE, 2019). Bu sayıların önümüzdeki yıllarda çok daha fazla artacağı düşünülürse, teknolojiden bağımsız bir eğitim ve uygulamanın düşünülemeyeceği ifade edilebilir. $\mathrm{Bu}$ bağlamda öğrencileri ve eğitimcileri, teknolojiyi kullanma konusunda cesaretlendirmek gerekmektedir. Bireylerde yaşam boyu öğrenme aracılığıyla iyi bir eğitim düzeyine sahip olmak ve becerilerini sürekli geliştirmek için eğitim ihtiyacının arttığı, bu nedenle öğrenmenin yeni biçimlerinin gelişimi, yeni öğrenme-öğretme teknolojilerinin kullanımını içeren yetişkin öğrenmesini geliştirmek için daha fazla çaba gerektiği belirtilmektedir (Michinov vd., 2011). Bahsedilen çaba diğer eğitim alanlarında olduğu gibi hemşirelik eğitiminde de kendini göstermektedir. Günümüzde hemşirelik eğitiminde, teknolojik altyapıyla uyumlu bir şekilde olgular üzerinden, soruna dayalı öğrenim oturumları yapılabilmekte ve eleştirel düşünme ile klinik karar verme gibi becerilerin geliştirilmesinde bu yöntemlerden yararlanılmaktadır ( $\mathrm{Lu}$ ve Li, 2009). Ayrıca bu tür sistemler öğrencinin uygulama becerisini kalıcı olarak kazanması için istediği kadar tekrar yapabilme ve yaptığı eylemin sonucunu görebilme firsatı sunmaktadır (Kaveevivitchai 
vd., 2009). Yapılan bir çalışmada öğrenciler; bilgisayarlı simülatör ile verilen eğitimin, fiziksel değerlendirme becerilerini ve kendilerine olan güveni arttırdığını, hemşirelik eğitiminde zorunlu olması gerektiğini belirtmişlerdir (Bremner vd., 2006). Ayrıca öğrencilerin milenyum kuşağı ya da net $(Z)$ kuşağı olarak adlandırılan ve erken yaşlardan itibaren interneti kullanan bireylerden oluştuğu dikkate alındığında, yeni teknolojilerin hemşirelik eğitimine entegre edilmesi, öğrenmenin kalıcılığı açısından önemlidir (Krautscheid ve Burton, 2003).

Hemşirelikle ilgili birçok kuruluş ve topluluk hemşirelik mesleği için teknolojinin önemine dikkat çekmektedir. Amerikan Ulusal Hemşireler Birliği 2015 yılında hemşireler arasında teknolojik uygulamalara ilişkin bilginin artırılması ve hemşirelik bakım hizmetlerinin geleceğe daha iyi hazırlanması yönünde bir eylem çağrısı yapmıştır (Nursing, 2015). Ayrıca Dünya Sağlık Örgütü (DSÖ) tarafından yayınlanan altın standartlarda, teknolojiye paralel olarak öğretim yöntemlerinden elektronik öğrenmeye ve simülasyona yer verilmesi önerilmektedir (Organization, 2009). Hemşirelikle ilgili sivil toplum kuruluşları da teknolojik, bilimsel ve insan kaynakları açısından sürekli değişim gösteren sağlık bakım hizmetlerinde çalışan hemşirelerin yetiştirildiği hemşirelik eğitiminde teknoloji kullanımının gerekliliğini vurgulamaktadır. Örneğin American Nurses Ceredentialing Center, The International Council of Nurses ve Ulusal Hemşirelik Dernekleri (National Nurses Associations - NNAs), kanıt temelli hasta bakımını sağlamada bilgiye ulaşmanın gerekli olduğu günümüz klinik uygulama ortamlarına hemşirelik öğrencilerini hazırlayacak hemşirelik eğitim programlarına teknolojinin entegre edilmesi, yeni teknolojilerin kullanımı için fırsatların yaratılması gerektiğini vurgulamakta olup teknolojiyi hemşirelik eğitim ve uygulamalarının temeli olarak kabul etmektedir (Şenyuva, 2019).

Amerikan Hemşirelik Kolejleri Derneği (American Association of Colleges of Nursing $=$ AACN, 2005) ve Amerika Birleşik Devletleri (ABD) Hemşirelik Eyalet Kurulları Ulusal Konseyi (National Council of State Boards of Nursing=NCSBN, 2005) hemşirelik eğitiminde simülasyon ve online öğrenme yöntemlerinin kullanılmasının yararlı olduğunu bildirmektedir ((AACN), 2005; (NCSBN), 2005). ABD Ulusal Hemşirelik Birliği (National League for Nursing -NLN) hemşire eğitimcilerin, öğrencilerin öğrenmesini kolaylaştırarak öğrenme sürecini desteklemek için teknoloji kullanımını önermektedir ((NLN), 2005). 


\section{Hemşirelik Eğitiminde Teknoloji Kullanımın Önemi}

Hemşirelik eğitiminde kullanılan teknolojik yöntemlerle olgular üzerinden soruna dayalı öğrenim oturumları yapılabilmektedir. Ayrıca eleştirel düşünmeyle klinik karar verme gibi becerilerin geliştirilmesinde yararlanılmaktadır ( $\mathrm{Lu}$ ve $\mathrm{Li}, 2009$ ). Bu tür uygulamalar öğrenciye istediği kadar tekrar yapabilme firsatı sunmakta, beceriyi kalıcı olarak öğrenmesine yardımcı olmakta ve bilgisayar yazılımları sayesinde öğrencinin yaptığı eylemin sonucunu görebilme fursatı sunmaktadır (Kaveevivitchai vd., 2009). Yapılan bir çalışmada öğrenciler, bilgisayarlı simülatör ile verilen eğitimin fiziksel değerlendirme becerilerinde kendilerine güvenini arttırdığını, iyi ve kusursuz bir deneyim sağladığını, hemşirelik eğitiminde zorunlu olması gerektiğini düşündüklerini belirtmişlerdir (Bremner vd., 2006).

Hemşirelik eğitiminde teknolojinin kullanılmasının gelişen-değişen dünya ile geleneksel hemşirelik eğitiminde teorik bilgiyle klinik uygulama arasında var olan boşluk için köprü olabileceği savunulmaktadır (Alinier vd., 2006). Simülasyon eğitimi gibi teknolojik uygulamalar; iletişim, afetlerde takım çalışması gibi insan odaklı tüm meslekleri kapsayan genel becerilerin yanı sıra teknik konularda da uygulama imkânı veren olanaklar sunmaktadır (C. L. Foronda vd., 2017). Hemşirelik eğitiminde kullanılan teknolojilerden olan sanal gerçeklik, pek çok eğitimci tarafından uygulanmakta ve önerilmektedir (Dutile vd., 2011; Guise vd., 2012; Shaw vd., 2010). Artırılmış gerçeklik (Augmented reality) ve sanal simülasyon (virtual simulation) teknolojisi uygulamaları birçok alanda olduğu gibi hemşirelik eğitiminde gelişmektedir. Bu teknolojilerin ön çalışmalarının pedagojik değerlendirmeleri öğrencilerin öğrenme düzeylerini arttırabildiğine dair kanıtlar sunmaktadır (C. L. Foronda vd., 2017).

Bütün bu teknolojik gelişmelerin olumlu işlevlerine rağmen, hemşire eğitimi veren kişilerin bu gelişmelere ayak uydurabilmelerinin ve onları hızlı dönüşüme hazırlayabilmelerinin eğitimin niteliği üzerinde kilit rol oynayacağı ifade edilebilir. Sağlık hizmetleri veren kişilerin eğitimi, mevcut ihtiyaçları karşılamanın yanı sıra gelecekteki talepleri öngörebilen ve ihtiyaç duyulduğunda gerekli hizmeti sunabilmeye ilişkin dengeli ve dinamik bir süreci temel almaktadır (Risling, 2017). Kuzey Amerika'da, bilişim alanındaki hemşirelik eğitimcilerine müfredat desteği sağlama konusunda önemli çalışmalar yapılmaktadır. 


\section{Hemşirelik Eğitiminde Kullanılan Teknoloji Uygulama Örnekleri}

$\mathrm{Bu}$ bölümde hâlihazırda hemşirelik eğitiminde kullanılmakta olan teknolojik uygulamalara ilişkin örnekler açıklanacaktır.

\subsection{Microsoft HoloLens}

Microsoft HoloLens karma bir sanal ve fiziksel gerçek sunan, kafaya monte edilmek üzerine tasarlanmış yeni nesil bir giyilebilir teknolojidir. Bu teknoloji kişinin öğrenme alanı içerisinde yüksek tanımlı holografik görseller sunmaktadır. Bu sistem farklı 1şıklandırma teknolojileri kullanarak insan vücudunun farklı katmanlarının üç boyutlu olarak bir görselini sunar. Örneğin anatomi ve fizyoloji eğitiminin niteliğini arttırmak için kas ve kemik katmanları çeşitli düzeylerde görselleştirilebilir. Bu teknoloji ile kadavra ihtiyacı büyük oranda karşılanabilir ve geleneksel eğitim modellerinin yerine üç boyutlu biçimlendirmeler ile öğrenmeler daha kalıcı hale getirilebilir (C. L. Foronda vd., 2017). Microsoft bu teknolojinin sağlık bilimlerinde eğitim amaçlı kullanımına yönelik olarak üniversite düzeyinde ortaklıklar yapma arayışındadır. İlerleyen dönemlerde çoklu disiplinlerde kullanımının artması öngörülmektedir (C. L. Foronda vd., 2017; Microsoft, 2019).

\subsection{BodyExplorer}

Artırılmış gerçeklik, gerçek dünyadaki nesnelerin ve mekânların, bilgisayar ortamındaki sanal öğeler aracılığıyla zenginleştirilmesiyle elde edilir (Altınpulluk, 2015; Samosky vd., (c) 2012). Diğer Artırılmış gerçeklik uygulamalarında olduğu gibi BodyExplorer uygulaması sanal ve fiziksel gerçekliği birleştirerek dijital ve fiziksel medyayı kombine etmektedir. Bu sistemin üst düzeyde kendi kendine öğrenme, otomatik denetim, bilişsel karar verme ya da iletişim gibi pek çok alanda hemşire eğitimini destekleyeceği düşünülmektedir (C. L. Foronda vd., 2017).

BodyExplorer, anatomi, fizyoloji ve klinik prosedürlerin "x-ray vision" şekliyle algılanmasını sağlamak için hasta simülatörünün üzerine monte edilmiş bir projektör kullanmaktadır (Samosky vd. (a), 2011). Fiziksel bir vücut modeli geliştirilmiş ve öğrencilere geri bildirim sağlamak için çeşitli sensörler ile donatılmıştır. Öğrenciler, model üzerinde fiziksel teması mümkün kılan stylus ( tablet ve bilgisayar üzerinde kullanılan ekran kalemi) 
temelli yeni nesil bir arayüz kullanarak hasta simülatörünün yüzeyinde pencereler açarak anatomik ve fizyolojik keşifler yapabilmektedirler. Uygulama pencereleri açıldığında, öğrenciler simülasyonu sağlanmış ilaçları uygulayabilir ve harici müdahalelerin simüle edilen hasta üzerindeki fizyolojik etkilerini görerek süreci yönetebilirler. Bir ilaç enjeksiyon sensörü, modele enjekte edilen gerçek sıvıları tespit ederek modelin gerçek bir hasta gibi otomatik tepki vermesini sağlamaktadır. Örneğin, öğrenciler intravenöz kalp ilacı verdiğinde, hastanın elektrokardiyogramdaki değişimleri görerek kalp atışının yavaşladığını izleyebilirler (Samosky vd. (b) , 2012).

Diğer artırılmış gerçeklik uygulamalarına ek olarak BodyExplorer, karma bir sanal ve fiziksel gerçeklik tasarımı kullanır, bu durum fiziksel uygulamalarda ekip koordinasyonunu desteklemektedir. İlaçları değerlendirme, order, hazırlama ve uygulama gibi becerileri geliştirmek için klinik cihazlar, çalışma ekibi ve simüle edilmiş bir vücut kullanarak bilişsel, fiziksel ve sözel etkileşim sağlayan bütünsel bir eğitim sağlayabilir. Bu sayede klinik uygulamaların temelini oluşturan hem bilişsel hem de psikomotor gelişimi eş zamanlı olarak sağlamak için büyük katkılar sağlar (C. L. Foronda vd., 2017).

\subsection{CliniSpace by Innovation in Learning, Inc}

CliniSpace, bir bilgisayar ekranında sanal bir sağlık bakım ortamının üç boyutlu bir gösterimini sunar. "Sanal dünya", akut bakım ünitesi, ofis, klinik veya hastanın evi gibi bir uygulama alanıdır. CliniSpace, web tabanlı ve çoklu kullanıcı özelliği sunan bir sistemdir. Bir başka deyişle birden fazla öğrencinin kişisel dizüstü bilgisayarlarına herhangi bir yerden giriş yapmasını mümkün kılmaktadır. Eğitim için tasarlanmış yeni nesil online interaktif oyun kurgusuna sahip fonksiyonel bir teknolojidir (Parvati vd., 2011). Öğrenciler hemşire, doktor veya yönetici gibi sanal karakterlerini seçerek, sanal akut bakım ünitesinde toplanırlar. Sanal ortamda oluşturulan klinik alanda, diğer kullanıcılarla sözel etkileşim sağlanmaktadır. Kullanıcı hasta ve etrafındaki ekipmanla çalışırken gerçek zamanlı bir konuşmaya katılmaktadır (Parvati vd., 2011). Bu sistemde sanal ortamdaki hasta, bilgisayar tarafindan otomatik olarak kontrol edildiği gibi başka bir kullanıcı tarafından manüel olarak kullanma seçeneği de sunulmuştur. Her sanal hastanın yaşamsal belirtileri, fiziksel görünümünü ve davranışını içeren fizyolojik bir modeli vardır. Fizyolojik değişkenler öğrencilerin müdahalelerine göre değişebilir ve bu 
değişimler eş zamanlı olarak gözlenebilir. Örneğin, intravenöz sıvıların verilmesi, kan hacminde bir artışa neden olur ve sanal hasta üzerinde kan basıncı değişimi olarak yansitılmaktadır (Parvati vd., 2011).

Öğrenciler yaşamsal belirtileri okumak, kalp ve nefes seslerini dinlemek, fiziksel bir değerlendirme yapmak, elektronik tıbbi kayıtları incelemek veya ilaç vermek için ortamdaki öğelere tıklayabilirler. Tüm eylemler izlenebilir ve geri bildirim için kullanılabilir niteliktedir. Sanal ortam öğrencilere gerçekçi senaryolar sunarak, bilgileri ve eylemleri keşfetmelerini sağlamaktadır. Ayrıca öğrenciler müdahale esnasında çevreden ve sanal hastadan geri bildirim almakta, işbirlikçi ekip çalışması deneyimiyle kalıcı öğrenmeleri sağlanmaktadır. Bu ortam; çatışma çözme veya meslek içi iletişim becerilerini geliştirmek için çoklu meslekleri birleştirme firsatı sunar (Parvati vd., 2011).

\subsection{Flight Simulator}

Akut bakım hemşire pratisyenlerini uçuş hemşireliğinde eğitmek için, Case Western Reserve Üniversitesi'ndeki Frances Payne Bolton Hemşirelik Okulu yüksek kalitede bir uçuş simülatörü geliştirmiştir. Sistem geliştirilmiş görseller ile sanki gerçek bir uçakta ve uçuş sırasında hissi uyandıracak şekilde tasarlanmıştır (C. L. Foronda vd., 2017).

Amerika Birleşik Devletleri Federal Havacılık İdaresi Ulaştırma Bakanlığg'na bağlı havacılık ile ilgili düzenlemeleri yapan devlet kurumu FAA (The Federal Aviation Administration) onaylı iç mekan, en gerçekçi uçuş hemşireleri, doktorlar, acil sağlık personeli ve ambulans personeli eğitimi için otantik tıbbi ekipman, havacılık kulaklıkları, emniyet kemerleri, radyolar ve hava tıbbi yatağıyla donatılmıştır. İki kamera, eğitim sırasında ve sonrasında sorgulamalara, araştırma analizlerine, sunumlara ve yayınlara ilişkin verileri kaydetmesi için gövde içine monte edilmiştir. $\mathrm{Bu}$ simülatör, akut bakım hemşiresi öğrencilerinin, gerçek bir hava tıbbi helikopterinin sınırları içinde kritik durumdaki bir hastayı tedavi etmek için gerçek uçuş ekipmanı kullanarak deneyim ve güven kazanmalarını sağlar. Sistem, artan güvenlik önlemleri gerektiren farklı ortamlar dahil olmak üzere mevsim, arazi, hava ve mekan şartlarına göre simüle ayarını değiştirebilir. Ayrıca hasta bakım senaryoları inme, septik şok, miyokard enfarktüsü, çoklu travma, yanıklar, diğer karmaşık tıbbi ve cerrahi 
durumlar gibi spesifik hasta koşullarına göre düzenlenebilir. Böylece saha öncesi uygulama eğitimiyle, ekipler için farklı uygulama imkanları sunarak bakım kalitesinin standartlaştırılmasını ve ekip üyeleri arasında işbirliğini sağlanmaktadır (C. L. Foronda vd., 2017; Simulator, 2014).

\subsection{Digital Clinical Experience}

Shadow Health tarafindan akademik araştırmaları temel alarak geliştirilen (Digital Clinical Experience), tıp, hemşirelik ve sağlıkla ilgili diğer eğitim kurumlarına yönelik web tabanlı bir sanal hasta uygulama paketini içermektedir. Bu teknoloji hemşirelik sürecinde klinik beceriler ve akıl yürütme becerilerinin uygulanmasına ve değerlendirilmesine olanak tanır. Ayrıca lisans, lisansüstü ya da uzmanlık eğitimi gibi farklı eğitim kademelerine yönelik modüller içermektedir (Health, 2019).

Digital Clinical Experience teknolojisi ile oluşturulan sanal ortamlar, her biri 100.000'den fazla soruyu tanıyıp yanıtlayabilen gerçekçi konuşma ve animasyon içeren 3 boyutlu sanal hastalar üzerinde uygulama eğitimi sunmaktadır. Bu teknoloji, öğrencilere hasta ile diyalog kurarken empati ve hasta bakımı için fırsatları tespit etme, kendi sorularını oluşturma ve sanal hastanın fiziksel muayeneleri yönetme özgürlüğü sağlar. Bu teknolojide modellenmiş sanal hastalar, çocuklardan yaşlılara veya çeşitli sosyokültürel farklılıklara sahiptir. Böylece çok farklı senaryo ve hasta öykülerini deneyimleme imkanı sunar (Health, 2019).

Bu teknoloji internet erişimi olan herhangi bir yerden kullanılabilir. Her simülasyonda, öğrenciler yönlendirilebilir, hasta görüşmesi gerçekleştirebilir, fiziksel değerlendirme yapılabilir, teşhis ve / veya bakım planları geliştirmek için bulgular belgelenebilir, gerekli gördüğü durumlarda müdahale edebilir. Ayrıca her senaryo uygulaması tekrar gözden geçirme ve ayrıntılı bir geribildirim sağlayabilir (C. L. Foronda vd., 2017; Health, 2019).

\section{6. vSim for Nursing}

Laerdal, Wolters Kluwer Health, and the National League for Nursing arasindaki işbirliği, vSim for Nursing ismiyle geliştirilen bu teknoloji, web tabanlı ve tek kullanıcılı bir sistem ile öğrencilerin sanal bir ortamda bilişsel hemşirelik becerilerini uygulamalarına izin 
vermektedir. Satın alınan pakete bağlı olarak; temel uygulamalar, farmakoloji, tıbbi-cerrahi simülasyonlar gebe, çocuk, yaşl1, yetişkin senaryo ekleriyle mevcuttur. Bu teknoloji nesnel bir ön test-son test özelliği sunarak anında geri bildirim içeren bir simülasyon performans puanı sağlar.

Elektronik sağlık kaydı sunan bu sistem, öğrencilerin hasta verilerinin nasıl organize edildiğinin yanı sıra bilgiye ulaşmaları için imkan sunar. Öğrencilere hastayı değerlendirme, orderları görüntüleme, ilaç verme ve hemşirelik uygulamalarını gerçekleştirme firsatı verir. Sanal hasta, öğrencinin hatalarını değerlendirmesini ve öğrenmesini sağlayan müdahalelere dayanarak yanıt vermek üzere modellendirilmiştir. Simülasyonda performans geri bildirimi sunan bu sistem ile öğrenciler, iyi performans gösterdikleri uygulamalarla iyileştirilmesi gereken becerilerinin neler olduğunu görmektedirler. Bu sanal simülasyon, öğrencilerin ev rahatlığında öğrenmelerine imkan sağlayarak performansı geliştirene kadar simülasyonu düzeltmek ve tekrar etmek için fursat sunmaktadır. Geliştirilen bu teknoloji öğrencilere imkan sınırlaması olmadan kendilerini geliştirmelerini sağlamaktadır. Vaka çalışması yapmak, klinik pratiği arttırmak ya da belli bir alanda uzmanlaşmak için klinik muhakeme, farmakoloji ve diğer hemşirelik uygulamalarında büyük avantajlar sağlayabilir (C. L. Foronda vd. , 2016).

\section{SONUÇ VE ÖNERILER}

$\mathrm{Bu}$ derlemede sağlık alanında teknoloji kullanımının eğitime yansımaları ve dünyada kullanılan farklı uygulamalara değinilmektedir. Hastanelerin personel giderlerinin büyük kısmını hemşirelere yapılan ödemeler oluşturmaktadır. Dünyada artan hemşire ihtiyacını göz önüne alırsak sağlık alanında yoğun teknoloji kullanımının zorunluluk olduğunu söyleyebiliriz. Klinik alanda değişen ve gelişen teknoloji olanaklarının eğitime yansıması kaçınılmaz bir durumdur. Hemşire eğitimcilerinin öğrencilerin mesleki gelişiminde kilit bir rol oynadığg, klinik bilgi ve beceri, sorun çözme, eleştirel düşünme yeteneklerinin geliştirilmesi için bu uygulamalardan faydalanılması gerektiği düşünülmektedir. $\mathrm{Bu}$ süreçte eğiticilerin ve öğrencilerin teknolojiyle desteklenmesi teori ve uygulama arasındaki boşluğun doldurulması ve hemşirelik hizmetlerinde kalitelinin sağlanması açısından son derece önemlidir. Ayrıca yapılan araştırmalardan elde edilen sonuçlarda sınırsız tekrar yapma ve yapılan uygulamanın 
sonuçlarını gözlemleme imkânı veren bu uygulamaların, öğrencileri motive ettiği, kaygılarını azalttığı ve kalıcı öğrenmeyi desteklediği belirtilmektedir.

Hemşirelik eğitimine destek amaçlı birçok teknolojik uygulama, öğrenme sürecinin mekandan bağımsız olması, sınırsız tekrar yapma imkanı ve sahaya çıkmadan gerekli becerilerin kazanılmasını temel almaktadır. Bu uygulamaların hem ülkelerin sahip olduğu alt yapıya hem de teknolojiyi kullanacak personelin yeterliliğiyle orantılı olarak başarıya ulaşabileceği ve sağlık sektöründe giderek daha büyük bir paya sahip olacağı öngörülmektedir. Gelişmiş ülkelerde teknolojinin hemşirelik eğitimi ve uygulamaları ile entegrasyonu göz önüne alındığında ülkemizde bu durumun yeterince yaygın olmadığı görülmektedir. Dolayısıyla ülkemizde hemşirelik eğitiminde teknoloji kullanımının artırılması ve hemşirelik eğitimi veren akademisyenlerin bu uygulamaları kullanmaya teşvik edilmesi ve bu konuda yetkinliklerinin sağlanması için gerekli düzenlemelere ihtiyaç olduğu anlaşılmaktadır.

\section{KAYNAKLAR}

(AACN), A. A. o. C. o. N. (2005). Faculty shortages in baccalaureate and graduate nursing programs: scope of the problem and strategies for expanding the supply. http:/labor.idaho.gov/ publications/ nursing/Supporting_Research.pdf.

(NCSBN), N. C. o. S. B. o. N. (2005). Clinical instruction in prelicensure nursing programs.

(NLN), N. L. f. N. (2005). Core competencies of nurse educators with task statements, competency 1 - facilitate learning. .

Alinier, G., Hunt, B., Gordon, R., \& Harwood, C. (2006). Effectiveness of intermediate-fidelity simulation training technology in undergraduate nursing education. Journal of advanced nursing, 54(3), 359-369.

Altınpulluk, H. (2015). Artırılmış gerçekliği anlamak: kavramlar ve uygulamalar. Açıköğretim Uygulamaları ve Araştırmaları Dergisi, 1(4), 123-131.

Bremner, M. N., Aduddell, K., Bennett, D. N., \& VanGeest, J. B. (2006). The use of human patient simulators: Best practices with novice nursing students. Nurse Educator, 31(4), 170-174.

Dutile, C., Wright, N., \& Beauchesne, M. (2011). Virtual clinical education: Going the full distance in nursing education. Newborn and Infant Nursing Reviews, 11(1), 43-48.

Eby, G. (2013). Uzaktan eğitim (uze) ortamlarının tasarımı: Yazılım mühendisliği yaşam döngüsü yaklaşımı. Ankara: Kültür.

Foronda, C. L., Alfes, C. M., Dev, P., Kleinheksel, A. J., Nelson Jr, D. A., O'Donnell, J. M., \& Samosky, J. T. (2017). Virtually nursing: Emerging technologies in nursing education. Nurse Educator, 42(1), 14-17. 
Foronda, C. L., Swoboda, S. M., Hudson, K. W., Jones, E., Sullivan, N., Ockimey, J., \& Jeffries, P. R. . (2016). Evaluation of vSIM for Nursing ${ }^{\mathrm{TM}}$ : A trial of innovation. . Clinical Simulation in Nursing,, 12(4), 128131.

Guise, V., Chambers, M., \& Välimäki, M. (2012). What can virtual patient simulation offer mental health nursing education? Journal of psychiatric and mental health nursing, 19(5), 410-418.

Health, S. (2019). Digital Clinical Experiences ${ }^{\mathrm{TM}}$. Retrieved from https://www.shadowhealth.com/

Heller, B. R., Oros, M. T., \& Durney-Crowley, J. (2009). The future of nursing education: Ten trends to watch.

HOOTSUITE, W. A. S. Y. (2019). Digital in 2019. Essential insights into Internet, Social media, Mobile and Ecommerce use around the world.

ITU. (2015). Figures-the world in 2015. Geneva: The International Telecommunication Union (ITU).

Karadağ, G., \& Uçan, Ö. (2006). Hemşirelik eğitimi ve kalite. Fırat Sağlık Hizmetleri Dergisi, 1(3), $42-51$.

Kaveevivitchai, C., Chuengkriankrai, B., Luecha, Y., Thanooruk, R., Panijpan, B., \& Ruenwongsa, P. (2009). Enhancing nursing students' skills in vital signs assessment by using multimedia computer-assisted learning with integrated content of anatomy and physiology. Nurse Education Today, 29(1), 65-72.

Krautscheid, L., \& Burton, D. (2003). Technology in nursing education: Oregon education-based technology needs assessment: Expanding nursing education capacity. Retrieved September, 26, 2008.

Lu, D. F., \& Li, Y. J. (2009). Effects of a web-based course on nursing skills and knowledge learning. Journal of Nursing Education, 48(2), 70-77.

Michinov, N., Brunot, S., Le Bohec, O., Juhel, J., \& Delaval, M. (2011). Procrastination, professional development. Washington, DC: American Nurses.

Microsoft. (2019). HoloLens 2. Retrieved from https://www.microsoft.com/en-us/hololens

Nursing, N. L. f. (2015). A VISION FOR The Changing Faculty Role: Preparing Students for the Technological World of Health Care.

Organization, W. H. (2009). Global standards for the initial education of professional nurses and midwives. Retrieved from

Parvati, D., Heinrichs, W., \& Patricia, Y. (2011). CliniSpace: a multiperson 3D online immersive training environment accessible through a browser. Medicine Meets Virtual Reality 18: NextMed, 163, 173.

Risling, T. (2017). Educating the nurses of 2025: Technology trends of the next decade. Nurse education in practice, 22, 89-92.

Samosky, J. T., Baillargeon, E., Bregman, R., Brown, A., Chaya, A., Enders, L., . . Weaver, R. A. (2011). Realtime" x-ray vision" for healthcare simulation: an interactive projective overlay system to enhance intubation training and other procedural training. Studies in health technology and informatics, 163, 549551. (a)

Samosky, J. T., Mikulis, B., Bregman, R., \& Nelson, D. A. (2012). A novel automated drug simulant recognition system for naturalistic real-time medical simulation. Paper presented at the MMVR. (b)

Samosky, J. T., Nelson, D. A., Wang, B., Bregman, R., Hosmer, A., Mikulis, B., \& Weaver, R. (2012). BodyExplorerAR: enhancing a mannequin medical simulator with sensing and projective augmented 
reality for exploring dynamic anatomy and physiology. Paper presented at the Proceedings of the Sixth International Conference on Tangible, Embedded and Embodied Interaction. (c)

Shaw, R. J., Johnson, C., \& Phillips, B. (2010). Using virtual environments to enhance nursing distance education. Creative nursing, 16(3).

Simulator, F. (2014). University installs nation's first critical-care transport helicopter simulator for flight nurse training. Retrieved from https://thedaily.case.edu/university-installs-nations-first-critical-care-transporthelicopter-simulator-for-flight-nurse-training/

Şendir, M. (2013). Kadın Sağlığı Hemşireliği Eğitiminde Simulasyon Kullanımı. Florence Nightingale Hemşirelik Dergisi, 21(3), 205-212.

Şenyuva, E. (2019). Reflections on Nursing Education of Technological Developments. Florence Nightingale Hemşirelik Dergisi, 27(1), 79-90.

van Houwelingen, C. T., Moerman, A. H., Ettema, R. G., Kort, H. S., \& ten Cate, O. (2016). Competencies required for nursing telehealth activities: A Delphi-study. Nurse Education Today, 39, 50-62. 